\title{
The "chemoinvasion assay": a tool to study tumor and endothelial cell invasion of basement membranes
}

\author{
ADRIANA ALBINI*, ROBERTO BENELLI, DOUGLAS M. NOONAN and CLAUDIO BRIGATI \\ National Cancer Research Institute, Genova, Italy
}

\begin{abstract}
Several genetic and epigenetic factors, both in the cell and in the host, contribute to the progression of tumors towards metastases. The escape of cancer cells from a primary, localized tumor to distant organs transforms a relatively curable pathology to an almost untreatable one. Metastatic lesions are often resistant to cancer therapy because of the progressive phenotypic changes that they have undergone. In this article we will give a bird's eye view on the features of metastatic cells and potential therapeutic targets. In particular, the invasion of basement membranes represents a fundamental step for cell dispersion. Over seventeen years ago we established the Matrigel "chemoinvasion" assay, a useful tool for studying the mechanisms involved in tumor and endothelial cell invasion of basement membranes and for the screening of anti-invasive agents. We will describe the assay and review some of the major results it enabled to obtain.
\end{abstract}

KEY WORDS: invasion, metastasis, angiogenesis, basement membrane, chemoinvasion

\section{Introduction}

Cancer invasion and metastasis is a highly complex and multistep process that requires a tumor cell to modulate its ability to adhere, degrade the surrounding extracellular matrix, migrate and proliferate at a secondary site; finally, tumors must also stimulate angiogenesis to attain macroscopic dimensions. During these steps, cells undergo a series of inter-related modifications, each of which may be rate-limiting. Tumor tissue tends towards chaos as cells progressively grow in the body as ectopic invaders. Genetic instability favors the acquisition of properties conferring growth, escape of control mechanisms and drug resistance. The natural history of a solid tumor can be exemplified into discrete, consequent steps: initiation, promotion, progression. Apart from the initial transforming event, several other factors come into play in the clinically relevant tumor. Inflammation is a common and potentially key feature of most tumors, as is neo-vascularization that permits an increase in size of the primary tumor. Subsequent to mutation/promotion signals, neoplastic cells eventually detach from the primary tumor and enter the circulation via the blood or lymphatic vessels; this is followed by their adhesion to the endothelium of distant organs. Usually, the end-result is extravasation and penetration into a new tissue. Sometimes, however, the tumor cells seem to be trapped in the vessel as an embolus (Chambers et al., 1995), perhaps because they are not capable of exiting due to local "defence" factors
(Osanai et al., 2002). When extravasation occurs, a secondary tumor takes place in a new location, the metastasis. Both the tumor and the host participate to this process.

The knowledge of these steps has given solid bases for planning new, specific therapies against metastasis. In order to assess the potential use of an anti-metastatic factor, appropriate models to evaluate malignancy are required. In vivo the most widely used models are the "experimental" and the "spontaneous" metastasis assays which assess extravasation and the complete metastatic process, respectively (Fidler 2002). However, it is often useful to dissect the metastatic process into single steps or groups of events by in vitrotechniques. A critical step in metastasis is the invasion of basement membranes.

Basement membranes are thin continuous sheets of compact extracellular matrix enveloping all organs and represent a barrier to macromolecules and cells. Originally, studies on invasion had been carried out using isolated basement membranes, particularly from the amnion (Liotta et al., 1980). One major simplification of these studies was the use of a reconstituted membrane, "Matrigel", which, when applied over filters in the Boyden chamber chemotaxis assay, allowed rapid quantification of the relative

Abbreviations used in this paper: BSA, bovine serum albumin; bFGF, basic fibroblast growth factor; HUVEC, human umbilical vein endothelial cells; TAM, tumor-associated macrophages; $\mathrm{uPA}$, urokinase plasminogen activator; VEGF, vascular endothelial growth factor.

*Address correspondence to: Dr. Adriana Albini. Istituto Nazionale per la Ricerca sul Cancro, Largo Rosanna Benzi 10, 16132 Genova, Italy. Fax +39-01-0573-7231. e-mail: adriana.albini@istge.it 
invasive potential of metastatic cells (Albini et al., 1987). This in vitro invasion was indeed found to correspond to metastatic potential in vivo within a wide variety of cell systems and, thanks to the soluble form of BM components found in cold matrigel, the assay is still widely used for testing cells with different invasive abilities.

During the dynamic process of tumor cell invasion, the cell activates specific proteases to set forth a local and limited degradation of matrix components. Matrix lytic enzymes are essential not only for moving through the stromal matrix barrier, but -more importantly- for intravasation and extravasation. The metalloproteinases (serine proteinases and cathepsins) have been the most thoroughly investigated with the chemoinvasion assay. Results obtained in the Boyden chamber matrigel assay have been a prelude to successful preclinical studies with protease- and in particular metalloproteinase- inhibitors. Examination of the effects on invasion by transfected and transduced cells has allowed this to become a rapid test for potential gene therapy agents as well.

During tumor neo-vascularization, the endothelial cells share features common to extravasating tumor cells. These include the ability to digest and cross the basement membrane. Angiogenesis represents a rate-limiting event for the metastasis of most solid malignancies, as the presence of blood vessels not only sustains tumor growth, but also facilitates metastatic dispersion through the bloodstream. Induction of endothelial cell invasion by tumor cell products and its inhibition has also been extensively studied in the matrigel invasion assay. We will describe the assay from a methodological point of view and review some of the data obtained on inhibitors of invasion with emphasis to the role of lytic enzymes and their inhibitors. Many of these factors have then been tested in clinical therapy.

\section{A brief note on transformation and growth as related to the invasive process}

One of the most important concepts established over the last decades is that initiation consists in a genetic lesion, meaning that the first step in (pre)malignancy corresponds to a DNA alteration. This kind of event generally does not lead to overt cancer; a second set of environmental/epigenetic factors are required for promotion, a process in which initiated cells begin to show a survival/proliferative advantage. Important recognized causes of promotion are a variety of irritants, organ resection, inflammation, phorbols (Coomber et al., 2003, Vorobtsova et al., 1993). They will ultimately contribute to disease progression when cells become apt to penetrate previously invincible barriers.

Stated in a simplistic form, mutations can cause either activation of a (proto)oncogene or inactivation of a tumor suppressor gene. Products of oncogenes of several families can contribute to transformation and progression. Genes linked to cell cycle/ apoptosis favor the expansion of different tumor cell subpopulations, while other genes encoding for proteins involved in the signal transduction cascade and cytoskeletal/microfilament rearrangement can interfere with adhesion, migration or invasion. Accordingly, inhibition of internal cell signaling machinery has been pointed as a possible route to control invasion (Wasilenko et al., 1996). The mechanisms of action of tumor suppression are varied: maintenance of chromosome stability, participation in the terminal differentiation process and the control of proliferation and survival. Tumor suppressors are often considered as safe-control components in the cell, able to transmit to the replication machinery a variety of growth-inhibitory signals. However, in the following paragraphs we will stress a possible involvement of oncosuppressors also in the control of the invasive phenotype.

The first oncosuppressor gene identified and cloned, Rb-1, has been demonstrated to also inhibit tumor cell invasion (Valente et al., 1996), in addition to tumor cell replication. Melanoma and osteosarcoma cells transduced to over-express $\mathrm{Rb}$ resulted in cells with a strongly reduced invasive potential. The oncosuppressor p16/CDKN2 is also an inhibitor of invasion. This effect does not seem to be simply due to growth reduction. In fact the oncosuppressor p53, although reducing the growth rate of transfected cells, was a weaker inhibitor of invasion. There appears to be a down-regulation of metalloproteinase activity by specific oncosuppressors, a phenomenon that will be extensively described later on.

Genes which are up-regulated in tumor progression often act as inducers of metalloprotease (MMP) production (Baruch et al., 2001). Typical examples are Bcl-2 and N-Myc: Ricca et al. showed that the expression of bcl-2 in mammary carcinoma cells enhanced NF-kB-dependent transcriptional activity (Ricca et al., 2000). Mobility-shift analysis revealed an increase of NF-kappaB DNA-binding in $\mathrm{Bcl}$-2-over-expressing clones that correlated with lower levels of the NF-kappaB cytoplasmic inhibitor lkappaBalpha. This pathway is able to activate the MMP-9 promoter, explaining the increased invasive potential of cells expressing Bcl-2. It was also shown, in neuroblastoma cell lines, that coexpression of $\mathrm{N}$ $\mathrm{Myc}$ and $\mathrm{Bcl}-2$ leads to increased tumorigenic properties (Noujaim et al., 2002). MMP-2 expression and secretion were increased in cells expressing Bcl-2 alone, or both $\mathrm{N}-\mathrm{Myc}$ and $\mathrm{Bcl}-2$. However, $\mathrm{MMP}-2$ activity was increased in the $\mathrm{Myc} / \mathrm{Bcl}-2$ cells yet remained unchanged in $\mathrm{Bcl}-2$ cells. This appeared to be due to TIMP-2 expression, which likely represses MMP-2 activity, as this was found high in $\mathrm{Bcl}-2$ cells but absent in $\mathrm{N}-\mathrm{Myc} / \mathrm{Bcl}-2$ cells. Accordingly, invasion was increased in N-Myc/Bcl-2 cells and prevented by the use of a pharmacological MMP-2 inhibitor. These observations suggest that $\mathrm{N}-\mathrm{Myc}$ and $\mathrm{Bcl}-2$ apparently cooperate to increase the expression, secretion and activation of MMP-2 in neuroblastoma.

The signaling pathways that mediate the normal functions of various growth factors are altered both during tumor progression and angiogenesis. Cytokines can also induce, in addition to growth, the migration, invasion and endothelial cell activation. Inhibition of growth factor interactions with their receptors is a prospective target for anti-metastatic and anti-angiogenic substances, as well as interference with the signaling cascade. Several growth factors and/or their receptors, as well as oncogenes involved in the signal transduction cascade, have been causally involved in induction of tumor cell and endothelial cell motility and invasion. For example, VEGF, a key growth factor, has an important role in metastasis and angiogenesis (Claffey and Robinson 1996, Ferrara et al., 2003). VEGF has more than one receptor. The higher affinity VEGF receptor is VEGFR1 (FIt-1), which has been closely linked to endothelial cell differentiation and capillary organization, while a lower affinity receptor, VEGFR2 (KDR/Flk-I), is responsible for the induction of the proliferative and invasive phases of angiogenesis. bFGF, with its numerous recep- 
tors, TGFs, HGF with its receptor c-met and many other growth factors are also linked to invasion and angiogenesis. Several cytokines, such as IL-1 $\beta$, bFGF, EGF and PDGF, act in invasion by inducing increased expression of one or more matrix metalloproteinases. Cytokines can also reduce matrix metalloproteinase expression: an example of this is TGF- $\beta$ repression of stromelysin induction, which is mediated at the level of transcription (Matrisian et al., 1992).

\section{Cell-cell adhesion disruption}

The suppression of cell-cell cohesion is critical for allowing the escape of the transformed cells during tumor progression to malignancy. An interesting example of these "zippers" linking cells to cells is E-cadherin, a key molecule in the maintenance of the architecture of epithelial tissues. Decreased expression of Ecadherin enhances the invasive and metastatic phenotype of transformed epithelial cells; this molecule is frequently inactivated in human epithelial cancers (Herbst et al., 2000). Restoration of functional $\mathrm{E}$-cadherin expression has been shown to revert an invasive epithelial tumor cell to a non-invasive phenotype. Cells expressing E-cadherin show an "epithelial" morphology, while those not expressing it have a "mesenchymal phenotype": E-cadherin thus appears to mediate the phenomena of epithelialmesenchymal transition. A well-studied example of epithelial cell activation causing cell-cell contact disruption is the "scattering" and invasion induced by HGF (scatter factor) which can be counteracted by E-cadherin. Both growth suppressive and motility-suppressive functions have been assigned to E-cadherin; mutational analyses suggest that these pathways can be independent. E-cadherin is linked to the cytoskeleton via P-catenin complex, which is in equilibrium with the product of another gene, found altered early in colon carcinogenesis, APC. Disruption of the $\beta$-catenin binding domain of $E$-cadherin has been shown to affect motility. E-cadherin-mediated growth suppression appears to be mediated through the p27/KIP1 cyclin-dependent kinase inhibitor, which in turn affects the phosphorylation state of the $\mathrm{Rb}$ gene product (Kouvaraki et al., 2002).

\section{Cell-extracellular matrix interaction}

Interactions between detached tumor cells and the stromal extracellular matrix occur via fibronectin, collagen, other glycoproteins and proteoglycans (Bogenrieder and Herlyn 2003, Casey et al., 2003, Esparza et al., 1999, Jiang and Couchman, 2003). This interaction bears consequences on the further evolution of tumor dissemination. The receptors for extracellular matrix proteins belong to the integrin family, a class of cell surface molecules consisting of an alpha-beta heterodimer. These molecules regulate cell adhesion, migration, growth and survival through complex signaling pathways. The VLA (very late antigen) heterodimers, formed with the $\beta 1$ subunit, are known to recognize various matrix molecules, often through an RGD (Arg-Gly-Asp) sequence. Tumor cell lines express a wide variety of integrins at their cell surface. RGD containing peptides and anti-integrin antibodies are inhibitors of cell adhesion and migration. Among the numerous integrins known, some have been extensively studied for their role in basement membrane invasion, particularly $\alpha 3 \beta 1, \alpha 6 \beta 1$ and $\alpha 6 \beta 4$.
$\operatorname{VLA} 3(\alpha 3 \beta 1)$ is a promiscuous receptor, recognizing fibronectin, collagen type IV and laminin, particularly laminin 5 (epiligrin). Alpha3 expression is enhanced in certain tumors and we found that $\alpha 3 \beta 1$ mediates migration and matrigel invasion of melanoma cells in the Boyden chamber assay (Melchiori et al., 1995). Interaction of VLA3 with laminin 5 stimulates invasion of malignant glioma cells. Signaling events induced by anti- $\alpha 3$ integrin antibodies may therefore be involved in invasion of tumor cells of various origin. Stimulation of the $\alpha 3 \beta 1$ receptor with antibodies induces MMP-2 activity in rhabdomyosarcoma and glioma cells, indicating that binding of this integrin receptor to its ligand can activate the proteolytic cascade necessary for invasion (Kubota et al., 1997). Published data suggest that inhibition of $\alpha 3 \beta 1$ could be of potential use in prevention of tumor cell invasion. Alpha3 and $\alpha 6 \beta 1$ integrins both associate with urokinase-type plasminogen activator receptors on cells attached to laminin, which could direct proteolysis for tumor cell invasion.

Alpha6beta4 is a receptor for the laminin family of matrix proteins that has been correlated with the progression of several tumors, particularly carcinomas. An $\alpha 6 \beta 4$ dependent increase in adhesion of colorectal carcinoma cells and invasion of Matrigel has been reported (Chao et al., 1996). Likewise, in fibrosarcoma cells, ribozyme suppression of $\alpha 6$ subunit expression abrogated lung metastasis and matrigel invasion. Up-regulation of the $\alpha 6 \beta 4$ receptor in breast cancer cells with TGF- $\beta$ or hormones, however, resulted in an anti-invasive effect corresponding to differentiation towards a myoepithelial phenotype. The complex role of $\alpha 6 \beta 4$ in adhesion, differentiation and migration requires further investigation to determine whether this receptor can be a target of antiinvasive therapy.

In addition to integrins, other matrix receptors such as the CD44, the hyaluronan receptor, may have a major role in malignancy. CD44 was originally shown to modulate melanoma cell invasion of collagen gels and later shown to modulate invasion of matrigel. Differing alternative splice variants of CD44 seem to confer invasiveness, although this appears to depend on the cell type (Wibulswas et al., 2002, Yoshinari et al., 1999). Addition of hyaluronan, the ligand for CD44, to matrigel dose-dependently enhances the invasion of glioma cells, although hyaluronan is not generally considered a major component of basement membranes.

\section{Interactions with the endothelium of the target organ}

Following growth, evasion from the primary tumor, escape from host immune system and survival of mechanical stress in the circulation, a malignant cell reaches the target organ. Interestingly, the final destination does not seem to be random, but may be heavily influenced by the interplay between the Sirens and Ulysses (chemokines/cytokines and their receptors) expressed by the site and the tumor (Muller et al., 2001). Typical are breast carcinoma cells which are believed to migrate in response to specific fatal attractors (Youngs et al., 1997).

The malignant cell eventually encounters the vascular endothelium of the target organ. Cell adhesion molecules (CAMs) expressed on the endothelial cell surface mediate attachment of malignant cells. It is generally believed that the initial interaction occurs during tumor cell rolling on top of endothelium through low affinity interactions; once the cell is retarded in its motion, higher 
affinity interactions (for instance through VCAM-integrin $\alpha 4 \beta 1$ interactions) take place, arresting the tumor cell on the endothelial cell surface. These events mirror those of normal leukocytes during their trafficking out of the blood stream. Metastatic cells tightly adhering to the endothelium induce endothelial cell retraction, cell surface uPA and plasmin and/or soluble factors may be involved. Certain cytokines, such as IL-1, may enhance these interactions and therefore favor metastasis. Numerous endothelial cell adhesion molecules, such as VCAM-1, ICAM-1 and Eselectin, are up-regulated on activated endothelial cells. Endothelial cell activation, for example exposure to IL- $1 \beta$, has been shown to increase expression of these cell-adhesion molecules and IL-1 $\beta$ expressing tumor cells show increased metastatic potential (Yano et al., 2003). In parallel, ligands for cell binding molecules on endothelial cell surface are increased on neoplastic cells. An example is E-selectin, which binds sialyl-Lewis(a) and sialyl-Lewis $(x)$ carbohydrates of mucins. Over-expression of mucins on tumor cells has been shown to increase adhesion to endothelial cells and increase invasion in the chemoinvasion assay. This corresponded to an increased metastatic potential, even though adhesion to laminin was reduced. Over-expression of ICAM-1, VCAM-1 and ELAM-1 might influence tumor progression in a variety of cancers. High expression of the VLA4 integrin, ligand for VCAM-1, in melanoma cells has been associated with increased metastatic potential although experimental over-expression appears to give the opposite results. Of course the strength of cell-cell interaction can shift an optimal adhesion, favoring migration and invasion, to a "glued" status blocking it.

\section{Basement membrane invasion and metastasis}

Historically, wars and invasions have been instrumental to dictators in distracting the local population from internal problems and to shift their frustration into an aggressive behavior towards the exterior, with the help of pervasive cultural mediators. By analogy, growing tumors have soon to face a nutritional decline, if not properly irrigated. Under the pressure of locally produced cytokines (the mediators), these cells arm themselves with barrier-disrupting enzymes and centrifugal forces start to prevail. Now a long journey is about to begin, in search of new settlements.

The way inflammatory cytokines can regulate the expression of MMP is mainly in the form of increased processing of MMP from the inactive zymogens to the active enzymes. Cytokines and their receptors can themselves be substrates of MMPs. The receptors can even be released from the cell membrane in the form of as sheddases or convertases, an event that can have serious consequences on internal cell signaling. Finally, cytokines recruit inflammatory cells into the tumor, which are also an important source of MMPs, in particular MMP-9 (Coussens etal., 2000). The role of inflammatory infiltrate within the tumor has traditionally been controversial, although an increasing body of evidence points to an active role of infiltrating cells, in particular macrophages, in stimulating growth and dissemination (Brigati et al., 2002, Coussens and Werb 2002, Liotta and Kohn 2001).

Alterations in the balance between proteolytic enzymes and their inhibitors (TIMPs, see below) appear to be a key feature of invasion. Although tumor cells themselves can show increased protease production, often these are derived from the host tissue in response to tumor cell stimulation. For the matrix metalloproteinases, sarcomas generally appear to show higher intrinsic metalloproteinase production, whereas for carcinomas, metalloproteinase production appears to be mostly derived from host stromal fibroblasts (Sato et al., 2004).

Endothelial basement membranes are barriers normally impermeable to migrating cells; however metastatic cells can breach them to enter the parenchyma of the target organ and proliferate, forming a secondary tumor or metastasis. Metastatic cells have been found to express significant amounts of matrix degrading enzymes, particularly metalloproteinases, serine proteases, cathepsins and others. Although several enzymes are involved in degradation of basement membrane, it appears that type IV collagenases, such as MMP-2 (gelatinase A, where gelatin is to be considered heat-denatured collagen) and MMP-9 (gelatinase B) play a key role. Others may be important in activation of these or other proteases, such as MT-MMPs (transmembrane cell surface MMPs) and stromelysins.

Most matrix metalloproteinases are synthesized as latent proenzymes with a signal sequence and propeptide segment that must be removed during activation, since the propeptide contains a conserved cysteine that interacts with the zinc in the active site. Accordingly, addition of exogenous synthetic $\mathrm{N}$-terminal peptide has been shown to inhibit MMP activity and invasion in vitro. Even an excess of cysteine alone has been shown to block MMP activity and reduce tumor metastasis in vivo.

Factors that increase MMP-2 expression also increase invasion and metastasis, for example IL-8. Interestingly, mechanical forces have also been shown to induce this protease (Haseneen et al., 2003). MMP-9 bears the intriguing feature of being produced also by non-transformed inflammatory cells infiltrating the tumor, such as TAM (van Kempen and Coussens 2002), an indeed dangerous liaison. MT-MMP has been reported to be a specific activator of MMP-2, such that carcinoma cells expressing MT-MMP on their surfaces can bind and activate MMP-2 derived from the host stroma (see Seiki et al., 2003 for review). Four different MT-MMPs have been identified so far.

The metalloproteinases interact with another major proteinase system regulating invasion: the plasminogen activator system. This consists of plasminogen activator (UPA, also produced as a latent proenzyme), its receptor (UPAR) and its inhibitor (PAI). UPA cleaves plasminogen to plasmin, which has a broad substrate specificity and degrades many components of the extracellular matrix. Plasmin (intriguingly) can be processed by several proteases such as MMP-12 and neutrophil elastase (Scapini et al., 2002) to angiostatin, a powerful anti-angiogenic and anti-inflammatory peptide. uPA can also directly activate metalloproteinases. Inhibitors of plasmin have been found to inhibit invasion into matrigel, while inhibitors of UPA delay invasion and stimulators of UPA production enhanced invasion. UPA must be bound to cell surface UPAR to affect invasion: interruption of this interaction leads to decreased invasion (Andreasen et al., 2000, Sidenius and Blasi, 2003). A peptide from uPA, ATF, has been reported to induce chemotactic and chemoinvasive capability. A complex relationship exits between UPA, UPAR and PAI-1. For example, UPAR binds vitronectin, this binding is enhanced by UPA and UPA-PAI-1 complexes, but is inhibited by PAI-1 alone. Such complex interactions may explain why conflicting data have been obtained with $\mathrm{PAI}$ regarding its role in invasion and about the use of UPA and PAI-1 as markers of malignancy. 
An inbalance between metalloproteinases and their natural tissue inhibitors (TIMPs) is a major factor inducing tumor cell invasion (Fassina et al., 2000). There are so far four natural inhibitors of the MMPs: TIMP-1, TIMP-2 and TIMP-3 and TIMP-4. TIMPs 1 and 2 have been shown to inhibit tumor cell invasion in vitro and to reduce metastasis in vivo. However, these molecules also display other activities as well, TIMP-2 has been reported to affect adhesion and apoptosis of melanoma cells. TIMP-1 affects both cell growth and survival. A striking example of non-MMP related activities is the potent anti-tumor activity induced by transfection of TIMP-3, apparently due to an enhancement of apoptosis. Therefore the MMPs and TIMPs are no longer considered to be involved only in matrix degradation and its regulation.

In addition to TIMPs, other natural compounds have been proven to be potent inhibitors of MMPs. For instance green tea gallate has been shown to blunt MMP-2 and -9 molecular shears (Garbisa et al., 1999). Also, a series of synthetic pharmacological inhibitors of MMPs have been developed. Among these, the prototype is Marimastat, whose predecessor was batimastat (BB94). These compounds have been shown to inhibit invasion in vitro and metastasis in vivo. Marimastat has shown suppression of tumor invasion metastasis and angiogenesis, but has been disappointing in clinical trials. Toxicity has been limited to skeletal muscle and is reversible. Other compounds have shown modest results, raising questions on the true efficacy of inhibiting MMPs alone, without treating inflammation, in advanced cancer (Wagenaar-Miller et al., 2004).

\section{Angiogenesis in tumor progression and anti-angio- genic approaches}

Neovascularization is rare under normal physiological conditions in adults and when it occurs, in wound healing or in the uterus during the oestrous cycle, it is strictly regulated. Naturally occurring inhibitors exert a rapid controlling influence over physiological angiogenesis. Vascularization of tumors is necessary to their survival, invasive growth and metastatic diffusion, much like ancient civilizations have prospered around rivers or water supplies. The early phase of angiogenesis, the degradation of basement membrane, which allows migration of endothelial cells towards the tumor, has mechanisms similar to those mentioned for metastatic cells. The identification of soluble factors stimulating the angiogenic cascade, as well as inhibiting it, have been made in vitroby using the chemoinvasion assay. Both metastatic and endothelial cells are targets of inhibition of integrin- mediated cell adhesion and migration. One of the major integrins involved in endothelial cell adhesion and migration is $\alpha v \beta 3$; it represents an intriguing target for cancer prognosis and therapy (Eskens et al., 2003, Gutheil et al., 2000) though its pilot trial in clinic has not shown significant effects. Protease inhibitors, developed as 'bullets' directed to the tumor cells, proved to be very effective inhibitors of tumor associated neo-vascularization.

Certain molecules seem to be specifically aimed towards the activated endothelium. One of the best known and studied molecules came from the observation of in vitro endothelial cell destruction by a fungal contamination. The pioneer studies of Ingber (Ingber et al., 1990, Kusaka et al., 1991) yielded a novel class of potentially useful anti-angiogenic factors, fumagillin and its derivatives (AGM- t470, chtoroacetylcarbanoyt) which inhibit endothelial cell proliferation even in the presence of saturating levels of basic fibroblast growth factor (bFGF). Angiostatin and endostatin, the more recent members of the anti-angiogenic drug family, were both derived from the urine or serum of mice bearing large primary tumors, confirming the hypothesis that tumor cells produce factors that retard the growth of their own metastasis.

Inhibitors of angiogenesis has followed several routes: antibody-mediated inhibition of growth factors, growth factor receptors and their interaction, has been a cardinal strategy, but small peptidomimetics and sulphonate compounds have also shown beneficial effects. Anti VEGF antibody Avastin can also be suited for treatment of metastatic colorectal cancer in combination with chemotherapy (Zhu and Willett 2003). Most of these compounds have shown to inhibit endothelial cell invasion of basement membranes. Furthermore, molecules with a long story of biomedical applications have had a 'revival' as anti-angiogenic compounds. Class I interferons have anti-angiogenic effects by controlling either bFGF -dependent endothelial cell stimulation or metalloprotease production and they are good inhibitors of endothelial cell invasion in vitro. Differentiative agents, such as retinoids, are also generally capable of preventing tumor invasion, although the opposite effect has been observed in the case of the promyelocytic NB4 leukemia cell line (Zang et al., 2000), indicating that caution is needed before transforming an observation into a postulate.

\section{The method}

\section{Matrigel preparation and composition}

Matrigel is prepared from the murine EHS tumor grown in vivo as previously reported (Vukicevic et al., 1992) or obtained commercially. Tumors are removed from the mice, snap-frozen in liquid nitrogen and stored at $-80^{\circ} \mathrm{C}$ until a sufficient quantity is obtained. The frozen material is then homogenized in $3.4 \mathrm{M} \mathrm{NaCl}$ with $50 \mathrm{mM}$ Tris, $4 \mathrm{mM}$ EDTA and $2 \mathrm{mM} \mathrm{NEM}$ and the insoluble material pelleted and saved. This is repeated 3 times, followed by extraction twice with $2 \mathrm{M}$ urea with $50 \mathrm{mM}$ Tris and $150 \mathrm{mM} \mathrm{NACl}$. The soluble material from these extracts is saved and dialyzed against $50 \mathrm{mM}$ Tris, $150 \mathrm{mM} \mathrm{NACl}$ and eventually DMEM at $4^{\circ} \mathrm{C}$. The preparation is sterilized by addition of a few drops of chloroform in the final dialyses. The final extract is stored frozen at concentrations ranging from $12-18 \mathrm{mg} / \mathrm{ml}$. The main components of this mixture are laminin, collagen IV, entactin (nidogen) and

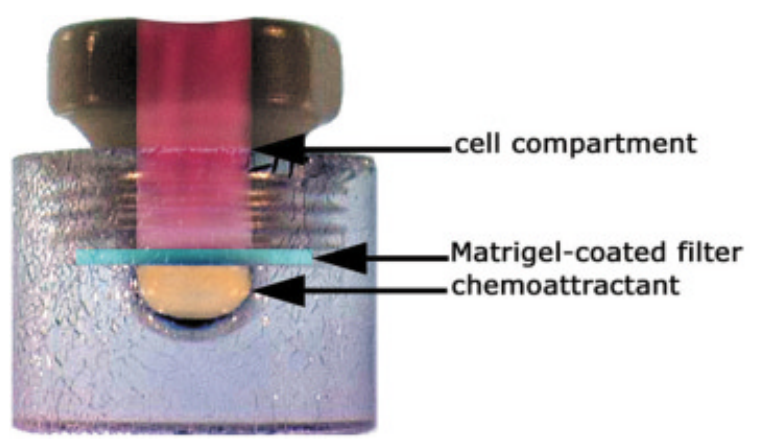

Fig. 1. Diagrammatic representation of a Boyden chamber (see text for details). 

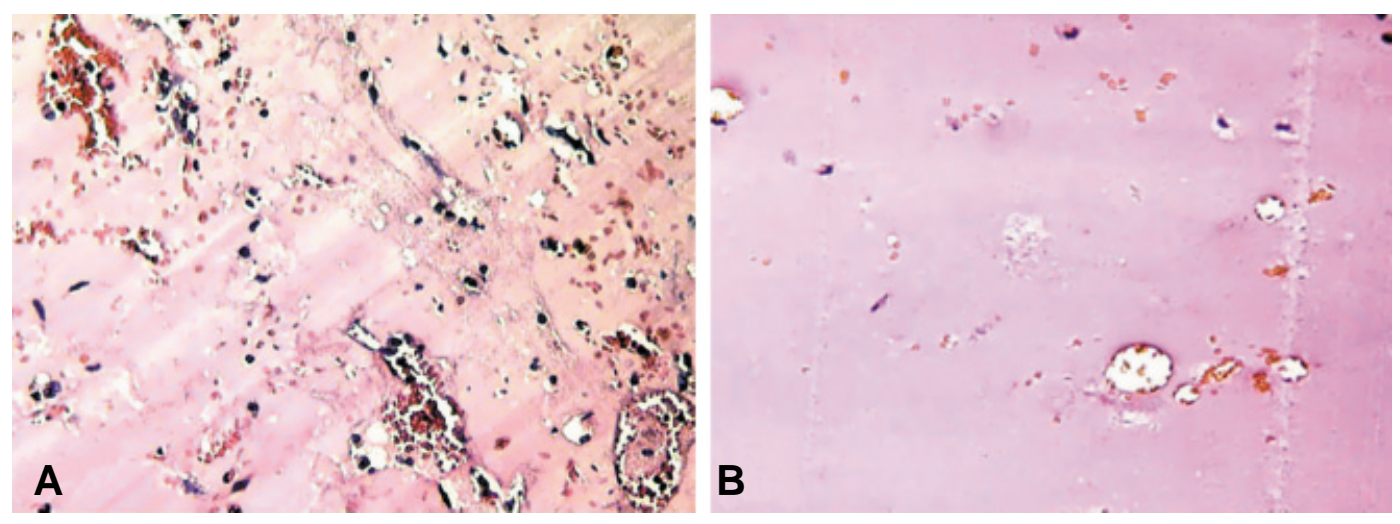

Fig. 2. Histology of paraffin sections of untreated (A) and inhibitor-treated (B) matrigel sponges containing angiogenic factors, recovered from a fourday in vivo angiogenesis experiment. Analysis was performed by standard hematoxylin-eosin staining.

perlecan; minor components are growth factors, collagenases, plasminogen activators. Commercially prepared matrigel is generally supplied in aliquots at $10-14 \mathrm{mg} / \mathrm{ml}$ (Becton Dickinson, Bedford, MA).

\section{The chemoinvasion assay}

Early methods aimed at quantifying cellular invasive activity by the use of filtered chambers date back to 1978 (Hart and Fidler, 1978) with diverse modifications (Hendrix et al., 1987). In the chemoinvasion assay we originally described, Boyden chambers were used (Fig. 1). Polycarbonate filters ( 8 or $12 \mu \mathrm{m}$ pore, depending on the cell size PVP-free from Nuclepore, Concorezzo, Milan, Italy) are coated with Matrigel diluted with water (10-100 $\mu \mathrm{g} / \mathrm{filter}$ ). Since matrigel tends to polymerize at temperatures above $4^{\circ} \mathrm{C}$, the dilutions in water are carried out on ice. We first perform a 1:2 dilution, to obtain a homogenous stock and then the final dilution. Filters are placed on sterile tissue culture plates under a laminar flow hood and liquid matrigel ( $50 \mu \mathrm{l}$ for $13 \mathrm{~mm}$ diameter filters) of diluted matrigel are pipetted onto the filter. During this step care must be taken to insure that the matrigel solution is applied even over most of the surface of the filter, leaving a small border of uncoated filter to prevent leakage off the filter. The matrigel coated filters are then dried under laminar flow. The filters are re-hydrated just before performing the assay using cold, serum free DMEM. This procedure leads to an even reconstitution of the matrigel coating on the filter surface. The amount of matrigel to be applied must be determined empirically for each experimental system. Generally, the density of the coating influences migration time and
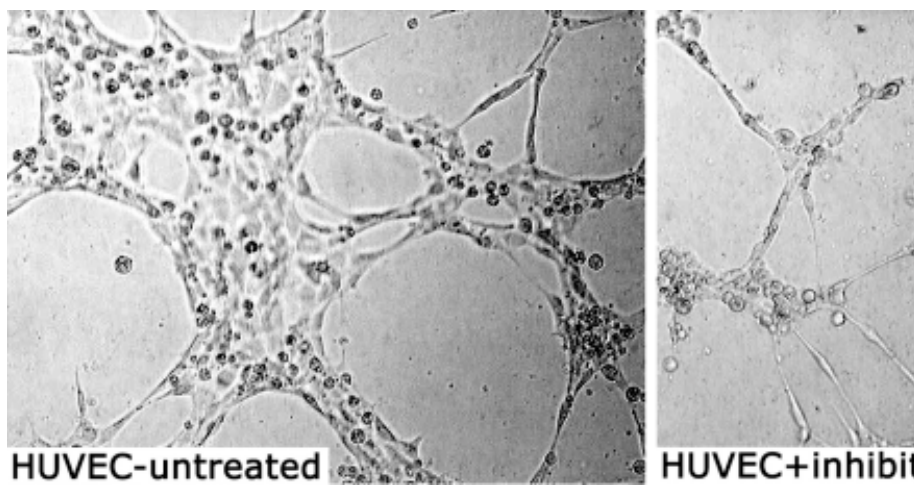
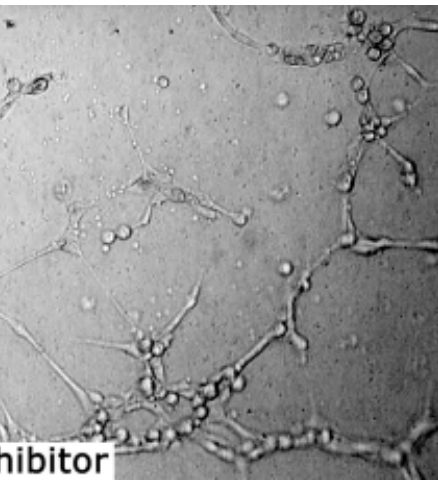

more aggressive metastatic cells are able to cross higher amounts of matrigel. A suitable filter pore size $(5,8,10,12 \mu \mathrm{m})$ for the cell type must also be used, this is generally that which gives good selectivity in chemotaxis assays. Numerous substances can be used as chemoattractants in the chemoinvasion assay. Good standard references are fibroblast conditioned medium for tumor cells, reproducing an attraction induced by stromal products, or Kaposi's Sarcoma cell conditioned medium for endothelial cells, mimicking a highly angiogenic environment. Purified single growth factors are also frequently used, such as EGF for epithelial cells or vascular endothelial growth factor (VEGF) for endothelial cells. Serum-free medium containing $0.1 \%$ bovine serum albumin (BSA) is used as negative control. Generally, chemotaxis assays are done in parallel to determine if treatments affect chemotaxis itself or if they are specific for invasion. An invasion index (invasion/ chemotaxis) can be calculated and indicates the specific contribution of matrix degradation using the following formula:

$$
\text { Invasion index }=\frac{\text { Invaded Cells }}{\text { Migrated Celts }} \times 100
$$

Under control conditions, without stimulation from a 'chemoinvasive' agent in the lower compartment, cells do not invade. Cells are harvested with trypsin (or just EDTA), washed with serum-free DMEM with $0.1 \% \mathrm{BSA}$ and placed in the upper compartment of the Boyden chamber (usually about $1.3 \times 10^{5}$ cells in $400-800 \mu \mathrm{l})$. Chambers are then incubated at $37^{\circ} \mathrm{C}$ in $5 \% \mathrm{CO}_{2}$, for $6 \mathrm{~h}$. For "checkerboard" analysis of invasion increasing concentrations of the same chemoattractant are also added to the cells. Invasion inhibitors acting on the chemoattractant are added to the lower compartment, while inhibitors acting on the cells or cell products, for instance blocking protease secretion or activation, are generally added along with the cells. Biological response modifiers, such as interferon, often require a pretreatment of the cells ( $24 \mathrm{~h}$ or longer) before chemoinvasion is performed. At the end of the incubation time, cells

Fig. 3. Morphogenesis in matrigel. Panels show untreated and inhibitor-treated HUVEC. 
remaining on the upper surface of the filter are mechanically removed by wiping them with a cotton swab or stripping on a glass slide. The cells migrated to the under surface are quantitated after staining (with toluidine blue, hematoxylin/eosin or others). In the original assay quantitation was performed by microscope counting five to ten random fields for each filter. Assays are generally performed in triplicate and repeated two or three times.

Numerous modifications have been proposed, including the use of other chamber types, novel detection methods such as colorimetric analysis of stained cells, image analysis and metabolic labeling with MTT or similar compounds. Finally, alternatives to matrigel have also been applied. If the assay is performed under sterile conditions, the invaded cells can be recovered and expanded, generally resulting in a population more invasive in comparison to the initial one.

One common alternative to Boyden chambers and single filters are either multiwell, or transwell ${ }^{\mathrm{TM}}$ chambers coated with matrigel. Transwell chambers have the advantage of sterility and "industrial" standardization, however the efficiency of invasion is lower (thicker coating requires longer assay times) and is more costly. Boyden chambers are recyclable and, if enough are available, it is easy to process about 30 samples per day.

Endothelial cells, such as HUVEC, can be tested using the same protocol. Generally, the coating of matrigel required to block invasion in the absence of a stimulus is lower, since the endothelial cell "aggressiveness" is far below that of most metastatic tumor cells.

\section{In vivo matrigel angiogenesis assay}

Passaniti et al. (1992) developed a matrigel-based in vivo angiogenesis assay which we have used extensively with modifications (Albini et al., 1994). Further modifications have been recently proposed (Akhtar et al., 2002, Malinda 2003) including the possibility of subcutaneous implantion of chambers (Kragh et al., 2003).

In our original version, angiogenic factors such as VEGF or IL-8 are mixed with liquid matrigel at $4^{\circ} \mathrm{C}$ and brought to a final volume of $600 \mu \mathrm{l}$. This suspension is then slowly injected subcutaneously into the flank of mice, where the matrigel polymerizes to form a solid gel. Several compounds such as inhibitors or specific antibodies can be added to the mixture as desired. Four days later, gels are recovered, weighed and divided in two parts: one is fixed in formalin and embedded in paraffin and the other is minced, diluted in water to measure the hemoglobin content with a Drabkin reagent kit 525 . The final concentration of hemoglobin is calculated from a standard calibration curve.

This assay also offers the potential to obtain detailed information concerning the microenvironement infiltrating the pellet, standard hematoxylin-eosin histological examination can be used to assess cell number and morphology (Fig. 2). Immunohistochemistry can help in identifying specific cell phenotypes. In this case, cryostat sections are sometimes better suited if certain antibodies are to be utilized.

\section{Growth and morphogenesis on Matrigel}

Matrigel can also be used for morphological studies on tumor and vascular cell invasion in vitro. Matrigel is thawed at $0^{\circ} \mathrm{C}$ in an icewater bath and $50 \mu \mathrm{l}$ of a concentrated solution $(10 \mathrm{mg} / \mathrm{ml})$ are pipetted into $13 \mathrm{~mm} /$ diameter tissue culture wells, avoiding even small bubbles. The matrigel is then polymerized for $1 \mathrm{~h}$ at $37^{\circ} \mathrm{C}$. Once polymerization has occurred, $5 \times 10^{4}$ cells in $1 \mathrm{ml}$ of final volume are carefully pipetted on top of the gel. These suspensions are mixed several times to ensure separation into single cells before plating. The plates are then incubated at $37^{\circ} \mathrm{C}$ in a $5 \% \mathrm{CO}_{2}$ humidified atmosphere. The assays are monitored and photographed with an inverted microscope; a modification using MTT as a colorant has been also described.

In this assay non tumorigenic cells generally do not grow. Low metastatic tumor cells form large round colonies, while high metastatic cells form branching, invasive colonies. Endothelial cells form interconnected networks in the matrigel that is enhanced by factors which stimulate angiogenesis and blocked by anti-angiogenic compounds. They seem to emerge as alternate coalescence around nodes and subsequent branching, following what seems a beautiful, common scheme for several natural and social aggregation patterns: a true D'Arcy Thompson delight! (See Strong et al. (2003) and Fig. 3).

\section{A final note on the "miraculous" virtues of these assays}

The systems described above have provided investigators several advantages: in the basic science field, these include possibility of learning the intimate mechanisms of cell movement, invasion and differentiation. On the filter-recovered invasive cells, microarray analysis could potentially establish the global expression profiling and molecular signatures of metastatic cells, refining current approaches (Brem et al., 2001, Welch, 2004). Molecular players of cell movement as diverse as growth-cone elongation in sensory neurons (McGuire and Seeds, 1990) or spreading of nevus melanocytes (Vink et al., 1994) have also been analyzed and resolved by these systems.

In the applicative field, major breakthroughs have been the correlation between in vitrobehavior on matrigel and in vivometastasis potential (Mullen, 2004) and the possibility of analyzing cell lines and their clones under a myriad of conditions (Luo et al., 1997). In the drug discovery field, a whole array of putative pharmacological modulators can be validated using these experimental platforms.

In a more clinical setting, a large cohort of biological fluids can be assessed for the presence of invasion-stimulating activities: for example lachrymal fluid, pleural fluid and serum after primary tumor resection (Stevenson et al., 2002, Tsunemi et al., 2003, Uchiyama et al., 1999).

Altogether, we can say that the inception of the matrigel era has deeply changed the way we look at tumor invasion; on the therapeutic side, the turf now is set for making the bench-to-bedside route, in dealing with tumors, less tortuous than ever.

\section{Acknowledgements}

We thank Simona Minghelli for the histology images. These studies were supported by grants from the AIRC (Associazione Italiana per la Ricerca sul Cancro), the Ministero della Salute Progetto Finalizzato, the MIUR Progetto Strategico, Progetto FIRB and the Compangia di San Paolo.

\section{References}

AKHTAR, N., E. B. DICKERSON and R. AUERBACH. 2002. The sponge/Matrigel angiogenesis assay. Angiogenesis 5: 75-80.

ALBINI, A., G. FONTANINI, L. MASIELLO, C. TACCHETTI, D. BIGINI, P. LUZZI, D. M. NOONAN and W. G. STETLER-STEVENSON. 1994. Angiogenic potential in vivo by Kaposi's sarcoma cell-free supernatants and HIV-1 tat product: inhibition of KS-like lesions by tissue inhibitor of metalloproteinase-2. Aids 8: 1237-44 
ALBINI, A., Y. IWAMOTO, H. K. KLEINMAN, G. R. MARTIN, S. A. AARONSON, J. M. KOZLOWSKI and R. N. MCEWAN. 1987. A rapid in vitro assay for quantitating the invasive potential of tumor cells. Cancer Res. 47: 3239-3245.

ANDREASEN, P. A., R. EGELUND and H. H. PETERSEN. 2000. The plasminogen activation system in tumor growth, invasion and metastasis. Cel/Mo/ Life Sci57: 25-40.

BARUCH, R. R., H. MELINSCAK, J. LO, Y. LIU, O. YEUNG and R. A. HURTA. 2001. Altered matrix metalloproteinase expression associated with oncogene-mediated cellular transformation and metastasis formation. Cell Biol Int 25: 411-20.

BOGENRIEDER, T. and M. HERLYN. 2003. Axis of evil: molecular mechanisms of cancer metastasis. Oncogene 22: 6524-36.

BREM, R., T. HILDEBRANDT, M. JARSCH, G. N. VAN MUIJEN and U. H. WEIDLE. 2001. Identification of metastasis-associated genes by transcriptional profiling of a metastasizing versus a non-metastasizing human melanoma cell line. Anticancer Res. 21: 1731-40.

BRIGATI, C., D. M. NOONAN, A. ALBINI and R. BENELLI. 2002. Tumors and inflammatory infiltrates: friends or foes? Clin Exp Metastasis 19: 247-58.

CASEY, R. C., T. R. OEGEMA, JR., K. M. SKUBITZ, S. E. PAMBUCCIAN, S. M. GRINDLE and A.P. SKUBITZ. 2003. Cell membrane glycosylation mediates the adhesion, migration and invasion of ovarian carcinoma cells. Clin Exp Metastasis 20: $143-52$

CHAMBERS, A. F., I. C. MACDONALD, E. E. SCHMIDT, S. KOOP, V. L. MORRIS R. KHOKHA and A. C. GROOM. 1995. Steps in tumor metastasis: new concepts from intravital videomicroscopy. Cancer Metastasis Rev 14: 279-301.

CHAO, C., M. M. LOTZ, A. C. CLARKE and A. M. MERCURIO. 1996. A function for the integrin alpha6beta4 in the invasive properties of colorectal carcinoma cells. Cancer Res 56: 4811-9.

CLAFFEY, K. P. and G. S. ROBINSON. 1996. Regulation of VEGF/VPF expression in tumor cells: consequences for tumor growth and metastasis. CancerMetastasis Rev. 15: 165-76.

COOMBER, B. L., J. L. YU, K. E. FATHERS, C. PLUMB and J. W. RAK. 2003 Angiogenesis and the role of epigenetics in metastasis. Clin Exp Metastasis 20: 215-27.

COUSSENS, L. M., C. L. TINKLE, D. HANAHAN and Z. WERB. 2000. MMP-9 supplied by bone marrow-derived cells contributes to skin carcinogenesis. Cell 103: 481-90.

COUSSENS, L. M. and Z. WERB. 2002. Inflammation and cancer. Nature 420: 860-7.

ESKENS, F. A., H. DUMEZ, R. HOEKSTRA, A. PERSCHL, C. BRINDLEY, S. BOTTCHER, W. WYNENDAELE, J. DREVS, J. VERWEIJ and A. T. VAN OOSTEROM. 2003. Phase I and pharmacokinetic study of continuous twice weekly intravenous administration of Cilengitide (EMD121974), a novel inhibitor of the integrins alphavbeta3 and alphavbeta5 in patients with advanced solid tumours. Eur J Cancer 39: 917-26.

ESPARZA, J., C. VILARDELL, J. CALVO, M. JUAN, J. VIVES, A. URBANOMARQUEZ, J. YAGUE and M. C. CID. 1999. Fibronectin upregulates gelatinase $\mathrm{B}$ (MMP-9) and induces coordinated expression of gelatinase A (MMP-2) and its activator MT1-MMP (MMP-14) by human T lymphocyte cell lines. A process repressed through RAS/MAP kinase signaling pathways. Blood 94: 2754-66.

FASSINA, G., N. FERRARI, C. BRIGATI, R. BENELLI, L. SANTI, D. M. NOONAN and A. ALBINI. 2000. Tissue inhibitors of metalloproteases: regulation and biological activities. Clin Exp Metastasis 18: 111-20.

FERRARA, N., H. P. GERBER and J. LECOUTER. 2003. The biology of VEGF and its receptors. Nat Med 9: 669-76.

FIDLER, I. J. 2002. Critical determinants of metastasis. Semin Cancer Biol 12: 89-96.

GARBISA, S., S. BIGGIN, N. CAVALLARIN, L. SARTOR, R. BENELLI and A. ALBINI. 1999. Tumor invasion: molecular shears blunted by green tea. Nat Med 5: 1216.

GUTHEIL, J. C., T. N. CAMPBELL, P. R. PIERCE, J. D. WATKINS, W. D. HUSE, D. J. BODKIN and D. A. CHERESH. 2000. Targeted antiangiogenic therapy for cancer using Vitaxin: a humanized monoclonal antibody to the integrin alphavbeta3. Clin Cancer Res 6: 3056-61.

HART, I. R. and I. F. FIDLER. 1978. An in vitro quantitative assay for tumor cell invasion. Cancer Res 38: 3218-24.

HASENEEN, N. A., G. G. VADAY, S. ZUCKER and H. D. FODA. 2003. Mechanical stretch induces MMP-2 release and activation in lung endothelium: role of EMMPRIN. Am J Physiol Lung Cell Mol Physiol 284: L541-7.
HENDRIX, M. J., E. A. SEFTOR, R. E. SEFTOR and I. J. FIDLER. 1987. A simple quantitative assay for studying the invasive potential of high and low human metastatic variants. Cancer Lett 38: 137-47.

HERBST, R., S. YANO, H. KUNIYASU, F. KHURI, C. BUCANA, F. GUO, D. LIU, B. KEMP, J. LEE, W. HONG and I. FIDLER. 2000. Differential expression of Ecadherin and type IV collagenase genes predicts outcome in patients with stage I non-small cell lung carcinoma. Clin Cancer Res 6: 790-7.

INGBER, D., T. FUJITA, S. KISHIMOTO, K. SUDO, T. KANAMARU, H. BREM and J. FOLKMAN. 1990. Synthetic analogues of fumagillin that inhibit angiogenesis and suppress tumour growth. Nature 348: 555-7.

JIANG, X. and J. R. COUCHMAN. 2003. Perlecan and tumor angiogenesis. J Histochem Cytochem 51: 1393-410.

KOUVARAKI, M., V. G. GORGOULIS, G. Z. RASSIDAKIS, P. LIODIS, C. MARKOPOULOS, J. GOGAS and C. KITTAS. 2002. High expression levels of p27 correlate with lymph node status in a subset of advanced invasive breast carcinomas: relation to $\mathrm{E}$-cadherin alterations, proliferative activity and ploidy of the tumors. Cancer 94: 2454-65.

KRAGH, M., P. J. HJARNAA, E. BRAMM, P. E. KRISTJANSEN, J. RYGAARD and L. BINDERUP. 2003. In vivo chamber angiogenesis assay: an optimized Matrigel plug assay for fast assessment of anti-angiogenic activity. Int $\mathrm{J}$ Oncol. 22: 305-11.

KUBOTA, S., H. ITO, Y. ISHIBASHI and Y. SEYAMA. 1997. Anti-alpha3 integrin antibody induces the activated form of matrix metalloprotease-2 (MMP-2) with concomitant stimulation of invasion through matrigel by human rhabdomyosarcoma cells. Int J Cancer 70: 106-11.

KUSAKA, M., K. SUDO, T. FUJITA, S. MARUI, F. ITOH, D. INGBER and J. FOLKMAN. 1991. Potent anti-angiogenic action of AGM-1470: comparison to the fumagillin parent. Biochem Biophys Res Commun 174: 1070-6.

LIOTTA, L. A. and E. C. KOHN. 2001. The microenvironment of the tumour-host interface. Nature 411: 375-9.

LIOTTA, L. A., W. C. LEE and D. J. MORAKIS. 1980. New method for preparing large surfaces of intact basement membrane for tumor invasion studies. Cancer Lett. 11: 141-147.

LUO, J., N. SHARMA, E. A. SEFTOR, J. DE LARCO, P. M. HEIDGER, M. J. HENDRIX and D. M. LUBAROFF. 1997. Heterogeneous expression of invasive and metastatic properties in a prostate tumor model. Pathol Oncol Res. 3: 264271.

MALINDA, K. M. 2003. In vivo matrigel migration and angiogenesis assays. Methods Mol Med 78: 329-35.

MATRISIAN, L. M., G. L. GANSER, L. D. KERR, R. W. PELTON and L. D. WOOD. 1992. Negative regulation of gene expression by TGF-beta. Mol Reprod Dev 32: 111-20.

MCGUIRE, P. G. and N. W. SEEDS. 1990. Degradation of underlying extracellular matrix by sensory neurons during neurite outgrowth. Neuron 4: 633-42.

MELCHIORI, A., R. MORTARINI, S. CARLONE, P. C. MARCHISIO, A. ANICHINI, D. M. NOONAN and A. ALBINI. 1995. The alpha 3 beta 1 integrin is involved in melanoma cell migration and invasion. Exp Cell Res 219: 233-42.

MULLEN, P. 2004. The use of Matrigel to facilitate the establishment of human cancer cell lines as xenografts. Methods Mol Med 88: 287-92.

MULLER, A., B. HOMEY, H. SOTO, N. GE, D. CATRON, M. E. BUCHANAN, T. MCCLANAHAN, E. MURPHY, W. YUAN, S. N. WAGNER, J. L. BARRERA, A. MOHAR, E. VERASTEGUI and A. ZLOTNIK. 2001. Involvement of chemokine receptors in breast cancer metastasis. Nature 410: 50-6.

NOUJAIM, D., C. M. VAN GOLEN, K. L. VAN GOLEN, A. GRAUMAN and E. L. FELDMAN. 2002. N-Myc and Bcl-2 coexpression induces MMP-2 secretion and activation in human neuroblastoma cells. Oncogene 21: 4549-57.

OSANAI, M., H. CHIBA, T. KOJIMA, M. FUJIBE, K. KUWAHARA, H. KIMURA, M. SATOH and N. SAWADA. 2002. Hepatocyte nuclear factor (HNF)-4alpha induces expression of endothelial Fas ligand (FasL) to prevent cancer celltransmigration: a novel defense mechanism of endothelium against cancer metastasis. Jpn J Cancer Res 93: 532-41.

PASSANITI, A., R. M. TAYLOR, R. PILI, Y. GUO, P. V. LONG, J. A. HANEY, R. R PAULY, D. S. GRANT and G. R. MARTIN. 1992. A simple, quantitative method for assessing angiogenesis and antiangiogenic agents using reconstituted basement membrane, heparin and fibroblast growth factor. Lab Invest 67: 519-28. 
RICCA, A., A. BIROCCIO, D. DEL BUFALO, A. R. MACKAY, A. SANTONI and M CIPPITELLI. 2000. bcl-2 over-expression enhances NF-kappaB activity and induces mmp- 9 transcription in human MCF7(ADR) breast-cancer cells. Int $\mathrm{J}$ Cancer 86: 188-96.

SATO, T., T. SAKAI, Y. NOGUCHI, M. TAKITA, S. HIRAKAWA and A. ITO. 2004 Tumor-stromal cell contact promotes invasion of human uterine cervical carcinoma cells by augmenting the expression and activation of stromal matrix metalloproteinases. Gynecol Oncol 92: 47-56

SCAPINI, P., L. NESI, M. MORINI, E. TANGHETTI, M. BELLERI, D. NOONAN, M. PRESTA, A. ALBINI and M. A. CASSATELLA. 2002. Generation of biologically active angiostatin kringle $1-3$ by activated human neutrophils. J Immunol 168 5798-804.

SEIKI, M., N. KOSHIKAWA and I. YANA. 2003. Role of pericellular proteolysis by membrane-type 1 matrix metalloproteinase in cancer invasion and angiogenesis. Cancer Metastasis Rev 22: 129-43.

SIDENIUS, N. and F. BLASI. 2003. The urokinase plasminogen activator system in cancer: recent advances and implication for prognosis and therapy. Cancer Metastasis Rev 22: 205-22.

STEVENSON, D., J. E. SCHECHTER, T. NAKAMURO, D. CHANG, N. Y. CHANG, M. PIDGEON, H. ZENG, A. K. MIRCHEFF and M. D. TROUSDALE. 2002. A new model system for studying lacrimal physiology using cultured lacrimal gland acinar cells on Matrigel rafts. Adv Exp Med Biol 506(Pt A):: 159-63.

STRONG, M., T. G. GRAEBER, M. BEEBY, M. PELLEGRINI, M. J. THOMPSON, T. O. YEATES and D. EISENBERG. 2003. Visualization and interpretation of protein networks in Mycobacterium tuberculosis based on hierarchical clustering of genome-wide functional linkage maps. Nucleic Acids Res 31: 7099-109.

TSUNEMI, T., S. NAGOYA, M. KAYA, S. KAWAGUCHI, T. WADA, T. YAMASHITA and S. ISHII. 2003. Postoperative progression of pulmonary metastasis in osteosarcoma. Clin Orthop. 407: 159-66.

UCHIYAMA, A., T. MORISAKI, K. BEPPU, M. KOJIMA, Y. MATSUNARI, A NAKATSUKA, K. MIZUMOTO, K. MATSUMOTO, T. NAKAMURA and M. TANAKA. 1999. Hepatocyte growth factor and invasion-stimulatory activity are induced in pleural fluid by surgery in lung cancer patients. Br J Cancer. 81: 721 -

VALENTE, P., A. MELCHIORI, M. G. PAGGI, L. MASIELLO, D. RIBATTI, L. SANTI, R. TAKAHASHI, A. ALBINI and D. M. NOONAN. 1996. RB1 oncosuppressor gene over-expression inhibits tumor progression and induces melanogenesis in metastatic melanoma cells. Oncogene 13: 1169-78.

VAN KEMPEN, L. C. and L. M. COUSSENS. 2002. MMP9 potentiates pulmonary metastasis formation. Cancer Cell. 2: 251-2.
VINK, J., S. K. DEKKER, R. L. VAN LEEUWEN, B. J. VERMEER, J. A. BRUIJN and H. R. BYERS. 1994. Role of beta 1 integrins in cell spreading and migration of human nevomelanocytes and dysplastic nevi cells on collagen type IV and laminin. Pigment Cell Res 7: 339-47.

VOROBTSOVA, I. E., L. M. ALIYAKPAROVA and V. N. ANISIMOV. 1993. Promotion of skin tumors by 12-O-tetradecanoylphorbol-13-acetate in two generations of descendants of male mice exposed to X-ray irradiation. Mutat Res 287: 207-16.

VUKICEVIC, S., H. K. KLEINMAN, F. P. LUYTEN, A. B. ROBERTS, N. S. ROCHE and A. H. REDDI. 1992. Identification of multiple active growth factors in basement membrane Matrigel suggests caution in interpretation of cellular activity related to extracellular matrix components. Exp Cell Res. 202: 1-8.

WAGENAAR-MILLER, R A., L. GORDEN and L. M. MATRISIAN. 2004. Matrix metalloproteinases in colorectal cancer: is it worth talking about? Cancer Metastasis Rev. 23: 119-35.

WASILENKO, W. J., A. J. PALAD, K. D. SOMERS, P. F. BLACKMORE, E. C. KOHN J. S. RHIM, G. L. J. WRIGHT and P. F. SCHELLHAMMER. 1996. Effects of the calcium influx inhibitor carboxyamido-triazole on the proliferation and invasiveness of human prostate tumor cell lines. Int J Cancer. 68: 259-64.

WELCH, D. R. 2004. Microarrays bring new insights into understanding of breast cancer metastasis to bone. Breast Cancer Res 6: 61-64.

WIBULSWAS, A., D. CROFT, A. A. PITSILLIDES, I. BACARESE-HAMILTON, P. MCINTYRE, E. GENOT and I. M. KRAMER. 2002. Influence of epitopes CD44v3 and CD44v6 in the invasive behavior of fibroblast-like synoviocytes derived from rheumatoid arthritic joints. Arthritis Rheum 46: 2059-64.

YANO, S., H. NOKIHARA, A. YAMAMOTO, H. GOTO, H. OGAWA, T. KANEMATSU, T. MIKI, H. UEHARA, Y. SAIJO, T. NUKIWA and S. SONE. 2003. Multifunctional interleukin-1beta promotes metastasis of human lung cancer cells in SCID mice via enhanced expression of adhesion, invasion and angiogenesis-related molecules. Cancer Sci 94: 244-52.

YOSHINARI, C., N. MIZUSAWA, H. R. BYERS and T. AKASAKA. 1999. CD44 variant isoform CD44v10 expression of human melanoma cell lines is upregulated by hyaluronate and correlates with migration. Melanoma Res 9: 223-31.

YOUNGS, S. J., S. A. ALI, D. D. TAUB and R. C. REES. 1997. Chemokines induce migrational responses in human breast carcinoma cell lines. Int J Cancer 71: 257 66.

ZANG, C., H. LIU, C. RIES, M. ISMAIR and P. PETRIDES. 2000. Enhanced migration of the acute promyelocytic leukemia cell line NB4 under in vitroconditions during short-term all-trans-retinoic acid treatment. J Cancer Res Clin Oncol. 126: 33-40.

ZHU, A. X. and C. G. WILLETT. 2003. Chemotherapeutic and biologic agents as radiosensitizers in rectal cancer. Semin Radiat Oncol. 13: 454-68. 